\title{
Mineração
}

\section{Separação de epídoto pelo fracionamento de estéreis da lavra de scheelita da Província da Borborema (RN)}

(Epidote separation from country rocks of the scheelite mineralization in the Borborema Province (RN, Brazil))

\author{
Eraldo Florêncio da Silva Junior \\ Bolsista de Iniciação Científica \\ Graduando em Engenharia de Minas \\ Universidade Federal de Pernambuco \\ E-mail:eraldo_florencio@click21.com.br \\ Pedro Luiz Guzzo \\ Doc. Sci. Cristalografia Aplicada \\ Professor Adjunto, Dep. de Engenharia de Minas \\ Universidade Federal de Pernambuco \\ E-mail:pguzzo@ufpe.br
}

\section{Resumo}

Esse trabalho apresenta uma proposta para efetuar, em escala de laboratório, a separação do epídoto presente em estéreis da lavra de scheelita da Província da Borborema. Para tanto, um fragmento de rocha foi britado e classificado em três faixas granulométricas, entre $150 \mu \mathrm{m}$ e $600 \mu \mathrm{m}$. A concentração do epídoto foi realizada em mesa vibratória, seguida de separação magnética usando o separador isodinâmico Franz. As frações magnética e não-magnética foram analisadas por difratometria e espectrometria por fluorescência de raios X. Para a faixa de 150 a $300 \mu \mathrm{m}$, foi possível efetuar a concentração do epídoto com um teor de $75 \%$ após quatro passagens pelo separador magnético usando correntes de 0,5 e 0,6 A, correspondendo a 0,5 e 0,6 T, respectivamente. Constatou-se que a fração de maior susceptibilidade magnética é constituída de andradita e que os principais contaminantes do concentrado de epídoto são a calcita, a andradita e o quartzo.

Palavras-chave: Epídoto, tactito, separação magnética, andradita, difratometria de raios $\mathrm{X}$.
Reiner Neumann

D.Sc. Mineralogia Aplicada, Pesquisador CETEM/

MCT. Centro de Tecnologia Mineral

E-mail:rneumann@cetem.gov.br

José Carlos da Silva Oliveira

Mestre em Engenharia Mineral

Professor Assistente, Depart. de Engenharia de Minas, Universidade Federal de Pernambuco

E-mail:zecarlos@ufpe.br

João Alves Sampaio

D.Sc. Engenharia Mineral, Tecnologista Sênior CETEM/MCT. Centro de Tecnologia Mineral E-mail:jsampaio@cetem.gov.br

\begin{abstract}
This paper presents a laboratory procedure to concentrate epidote from fragments associated with country rocks of the scheelite mineralization in the Borborema Province (Rio Grande do Norte, Brazil). A block weighting $17.5 \mathrm{~kg}$ was crushed and classified in grain sizes ranging from 150 to $600 \mu \mathrm{m}$. The concentration was carried out in a shaking table followed by four cycles of magnetic separation using a Frantz isodynamic separator with currents ranging from 0.5 and $0.6 \mathrm{~A}(0.5$ to $0.6 \mathrm{~T})$. The mineralogical characterization of the pre-concentrate and the fractions resultant from magnetic separation were carried out by $X$-ray powder diffractometry and $X$-ray fluorescence spectrometry. The separation of the epidote allowed close to $75 \%$ epidote for the $150 \times 300 \mu \mathrm{m}$ size class. The fraction with the highest magnetic susceptibility in the mineral assemblage was mainly composed of andradite. Calcite, andradite and quartz were found to be the contaminants within the concentrate.
\end{abstract}

Keywords: Epidote, tactite, magnetic separation, andradite, $X$-ray powder diffractometry. 


\section{Introdução}

Os minerais do grupo do epídoto (epídoto, zoisita, ortita) são silicatos de cálcio e alumínio hidratados, inerentes a uma grande variedade de paragêneses. Ocorrem disseminados em rochas formadas a partir de um metamorfismo de contato (por ex. tactitos) e também em rochas metassomáticas, hidrotermais, rochas ígneas félsicas ou, ainda, nos pegmatitos. Os minerais de epídoto ocorrem associados à clorita, calcita, vesuvianita, quartzo, piroxênios e granadas (Dana-Hurlbut, 1959, Frei et al., 2003).

O mineral epídoto tem fórmula $\mathrm{Ca}_{2} \mathrm{Al}_{2}\left(\mathrm{Fe}^{3+}, \mathrm{Al}\right)\left[\mathrm{SiO}_{4}\right]\left[\mathrm{Si}_{2} \mathrm{O}_{7}\right] \mathrm{O}(\mathrm{OH})$ e pertence ao sistema monoclínico, à classe $2 / \mathrm{m}$ (prismática) e ao grupo espacial $\mathrm{P} 2_{1} / \mathrm{m}$. As principais propriedades físicas do epídoto são: clivagem perfeita segundo $\{001\}$ e imperfeita segundo $\{100\}$; dureza Mohs entre 6 e 7; densidade entre 3,35 e 3,45 g/ $\mathrm{cm}^{3}$; brilho vítreo. Trata-se de um cristal biaxial negativo e sua coloração varia entre o verdeamarelado ao verde-escuro. Os parâmetros de sua cela unitária são a $=8,888 \AA$, $\mathrm{b}=5,628 \AA$, c $=10,152 \AA$ e $\beta=115,383^{\circ}$ (Dana-Hurlbut, 1959, Ralph \& Ralph, 2007).

O interesse geológico pelos epídotos reside no fato de que as estruturas cristalinas desses minerais podem incorporar elementos traços como $\mathrm{Pb}, \mathrm{Sr}, \mathrm{U}$, Th, Y e terras-raras importantes para a compreensão dos processos geoquímicos e geocronológicos (Frei et al., 2003). Ademais, o epídoto voltou a ser considerado no protocolo de datação pelo método dos traços de fissão, pois, recentemente, um novo procedimento de ataque químico foi proposto para aprimorar o processo de preparação de amostra para essa finalidade (Curvo et al., 2005).

Considerando suas recentes aplicações, o nosso interesse inicial foi investigar a sensibilidade da resposta termoluminescente do epídoto, dada a inemineral (Sullasi et al., 2007). Com isso, imediatamente fez-se necessário preparar alíquotas de alta pureza desse minexistência desse tipo de análise para esse ral. Como o epídoto apresenta densidade e susceptibilidade magnética comum a vários outros minerais, a preparação dessas alíquotas era até então limitada à catação manual de espécimes monocristalinas (Curvo, 2002). Nesse contexto, a partir de estéreis da lavra de scheelita da Mina Brejuí (Currais Novos, RN), foi estudado um procedimento em escala de laboratório para a separação desse mineral, usando métodos físicos de concentração. As análises por difratometria do pó e fluorescência de raios $\mathrm{X}$ das frações obtidas a partir da rota de concentração empregada mostram que a metodologia proposta pode ser empregada para obtenção de alíquotas de epídoto com pureza satisfatória.

\section{Materiais e métodos}

O fragmento utilizado nesse estudo foi coletado das encaixantes de tacti(Currais Novos, RN). A inspeção visual do fragmento (Figura 1a), com massa de 17,6 kg, indicou a presença de calcita, epídoto, quartzo e grãos de granada distribuídos em uma faixa avermelhada. Inicialmente, o bloco foi quebrado com uma marreta para obter pedaços adequados à britagem. Em seguida, foram retirados grandes monocristais de epídoto e calcita dos pedaços menores, com martelo e formão. A Figura 1b apresenta alguns

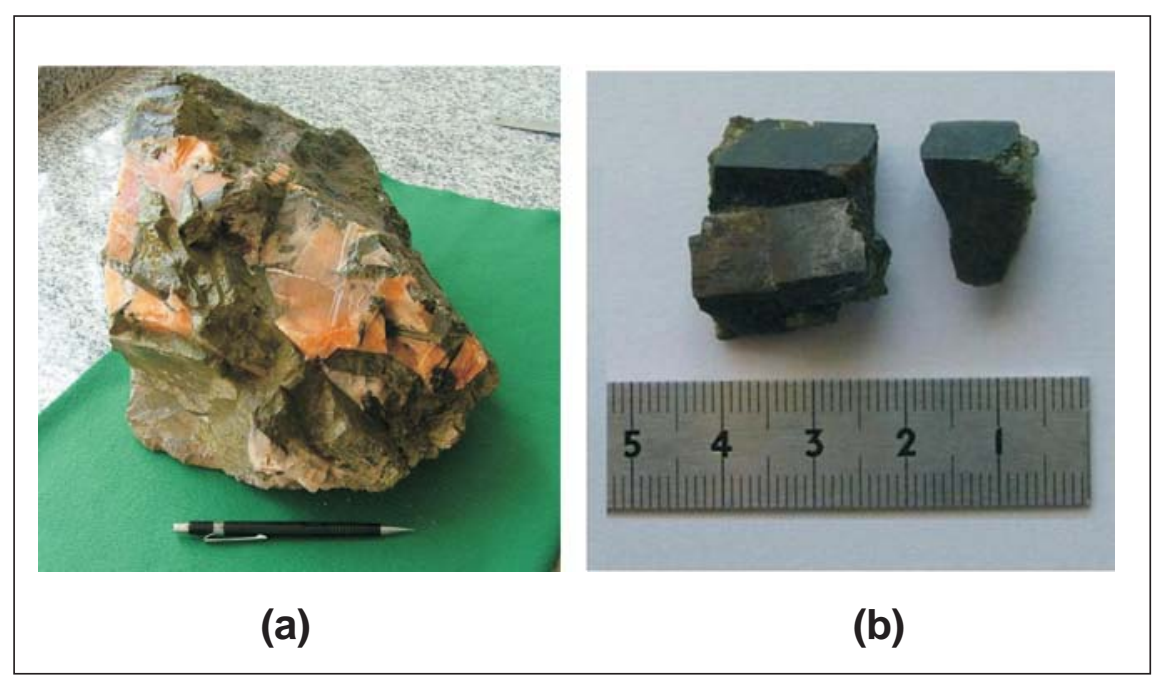

Figura 1 - (a) Bloco de tactito procedente dos estéreis da lavra de scheelita e (b) monocristais de epídoto extraídos do bloco.

monocristais de epídoto extraídos da amostra. Cerca de $6 \mathrm{~kg}$ do material fragem britadores de mandíbulas (duas etapas) e em um britador de rolos, até que todo material pudesse ser passado em malha de abertura de $1700 \mu \mathrm{m}$. O produto foi classificado em três faixas granulométricas: 300x600 $\mu \mathrm{m}, 150 \times 300 \mu \mathrm{m}$ e $<150 \mu \mathrm{m}$.

Para cada faixa granulométrica, a pré-concentração do epídoto foi realizada em mesa vibratória Wilfley $n^{\circ} 13$, operando com inclinação de aproximadamente $15^{\circ}$. As frações do pré-concentrado foram secadas e pesadas. A partir do pré-concentrado de epídoto, ensaios de separação magnética foram realizados com o separador isodinâmico Frantz, modelo L1, operando com inclinação de $15^{\circ}$ e nível de vibração entre 4 e 5 . A partir das susceptibilidades magnéticas dos minerais identificados visualmente, alguns valores de corrente elétrica (I) foram testados entre 0,3 A e 0,6 A, correspondendo à indução magnética entre 0,3 e 0,6 T. Antes, a remoção do material fortemente magnético foi realizada com um imã de mão de ferrite. Em seguida, testes com a faixa de 150 a $300 \mu \mathrm{m}$ foram realizados em alíquotas de 2,5 g com corrente de 0,5 A (0,5 T). A análise em lupa binocular mostrou que a fração magnética dessa separação, de coloração avermelhada, seria predominantemente consto da lavra de scheelita da Mina Brejuí mentado manualmente foram reduzidos

462 REM: R. Esc. Minas, Ouro Preto, 61(4): 461-466, out. dez. 2008 
tituída por granada e a fração não magnética, de coloração esverdeada com fragmentos claros e partículas avermelhadas, seria constituída de epídoto, calcita, quartzo e granada. Assim, visando a reduzir a presença de granada no concentrado de epídoto, foi realizada uma nova separação com corrente de 0,5 A. Para efeito de comparação, grãos preparados a partir de um monocristal de epídoto foram observados na lupa binocular. Para a remoção dos minerais fracamente magnéticos, a fração contendo epídoto foi fracionada usando agora uma corrente de 0,6 A. Obtiveram-se uma fração magnética com maior teor de epídoto e uma fração não-magnética composta por partículas de coloração verde-escura e esbranquiçada. A separação com corrente de $0,6 \mathrm{~A}$ foi repetida para a fração magnética para melhorar a qualidade do concentrado de epídoto. Esse procedimento foi adotado para concentrar cerca de 10 g de epídoto a partir de 30 g de pré-concentrado na granulometria de 150 a $300 \mu \mathrm{m}$. As frações resultantes foram cominuídas em almofariz de porcelana e classificadas nas malhas de $75 \mu \mathrm{m}$ e $150 \mu \mathrm{m}$. Obtiveram-se alíquotas de aproximadamente $5 \mathrm{~g}$ das frações do pré-concentrado (pós-mesa), concentrado final de epídoto e fração magnética final. Procedimento análogo foi realizado para o monocristal de epídoto.

A fração passante na malha de $75 \mu \mathrm{m}$ foi utilizada para efetuar a caracterização mineralógica das respectivas alíquotas mediante difratometria e espectrometria por fluorescência de raios X. Os difratogramas de raios $\mathrm{X}$, obtidos pelo método do pó, foram coletados num equipamento Bruker-AXS D4 Endeavor, nas seguintes condições de operação: radiação Co K $\alpha \pm(35 \mathrm{kV} / 40 \mathrm{~mA})$; velocidade do goniômetro de $0,02^{\circ}(2 \theta)$ por passo com tempo de contagem de $1 \mathrm{~s}$ por passo e coletados de 5 a $80^{\circ}(2 \theta)$. As interpretações qualitativas do espectro foram efetuadas por comparação com padrões contidos no banco de dados PDF 02 (ICDD, 2006) e software Bruker Diffrac ${ }^{\text {Plus }}$. O refinamento dos parâmetros de rede e a quantificação das fases foram executados pelo módulo FPM (Full
Profile Method) do mesmo software, após calibração das propriedades do equipamento utilizando um padrão de alumina- $\alpha$ rastreável a padrões do NIST, fornecida pela Bruker. Os teores dos elementos maiores foram obtidos por fluorescência de raios $X$, em equipamento Bruker-AXS S4 Explorer, a partir de amostras previamente pulverizadas em moinho vibratório de anel e prensadas a $200 \mathrm{kN}$, com fundo de ácido bórico. Utilizou-se a rotina de análise semiquantitativa (sem padrões) do fabricante para efetuar a determinação percentual dos teores dos óxidos constituintes.

\section{Resultados e discussão}

Os parâmetros da separação magnética foram obtidos em ensaios preliminares usando o pré-concentrado de epídoto oriundo da mesa. A Tabela 1 mostra a partição da amostra para as frações magnética (fN) e não-magnética (fNM) para as três faixas granulométricas e para as correntes analisadas. Considerando a susceptibilidade magnética dos minerais dominantes na amostra (calcita, epídoto, granada e quartzo), espera-se que o maior teor de epídoto ocorra na fração magnética. Logo, os resultados da Tabela 1 mostram que a separação desse mineral é mais eficaz para a faixa 150 a $300 \mu \mathrm{m}$.

A Figura 2a sintetiza o procedimento desenvolvido para realizar a separa- ção do epídoto na granulometria entre 150 a $300 \mu \mathrm{m}$. Optou-se por efetuar duas passagens para cada valor de corrente, visando a aumentar o teor de epídoto no concentrado. A Figura $2 b$ ilustra as frações magnética e não magnética resultantes do processo de separação para duas alíquotas. Visualmente, observa-se que as partículas do concentrado de epídoto têm coloração predominantemente esverdeada.

A Tabela 2 apresenta a partição em massa para as frações magnética e nãomagnética das alíquotas apresentadas na Figura 2b. A soma de fM e fNM para $\mathrm{I}=0,6 \mathrm{~A}$ corresponde à massa de $\mathrm{fNM}$ para $\mathrm{I}=0,5 \mathrm{~A}$. A fração magnética para $\mathrm{I}=0,6 \mathrm{~A}$ corresponde ao concentrado de epídoto. Usando o procedimento descrito na Figura 2a, cerca de 150 g de préconcentrado foram processados para a obtenção de epídoto para medida da resposta termoluminescente (Sullasi et al., 2007). Parte do material serviu para efetuar a caracterização mineralógica das frações magnética e não-magnética.

A Figura 3 apresenta os difratogramas de raios $\mathrm{X}$ da fração de pré-concentrado (pós-mesa), das frações magnéticas, para $\mathrm{I}=0,5 \mathrm{Ae} \mathrm{I}=0,6 \mathrm{~A}$, e da amostra de epídoto monocristalino. A análise comparativa com os padrões minerais mostrou que o pré-concentrado (e-pm) é constituído principalmente por epídoto, andradita, calcita e quartzo. O difratograma da fração tida como concentrado de epídoto (e-c) tem grande semelhança

Tabela 1 - Resultado da separação magnética do pré-concentrado de epídoto em função da corrente e da granulometria.

\begin{tabular}{c|c|c|c|c|c|c}
\hline Faixa $\rightarrow$ & \multicolumn{2}{|c|}{300 a $600 \mu \mathrm{m}$} & \multicolumn{2}{c|}{$\mathbf{1 5 0}$ a $\mathbf{3 0 0} \boldsymbol{\mu m}$} & \multicolumn{2}{c}{$<150 \mu \mathrm{m}$} \\
\hline $\mathrm{I}(\mathbf{A})$ & fM (\%) & fNM (\%) & fM (\%) & fNM (\%) & fM (\%) & fNM (\%) \\
\hline 0,3 & - & 100,0 & - & 100,0 & - & 100,0 \\
\hline 0,4 & 3,1 & 96,9 & 0,2 & 98,4 & 3,0 & 97,0 \\
\hline 0,5 & 14,7 & 85,3 & 17,5 & 82,5 & 14,8 & 85,2 \\
\hline 0,6 & 61,3 & 38,7 & 69,0 & 31,0 & 60,1 & 39,9 \\
\hline
\end{tabular}

- massa desprezível. fM: fração magnética. fNM: fração não magnética. 


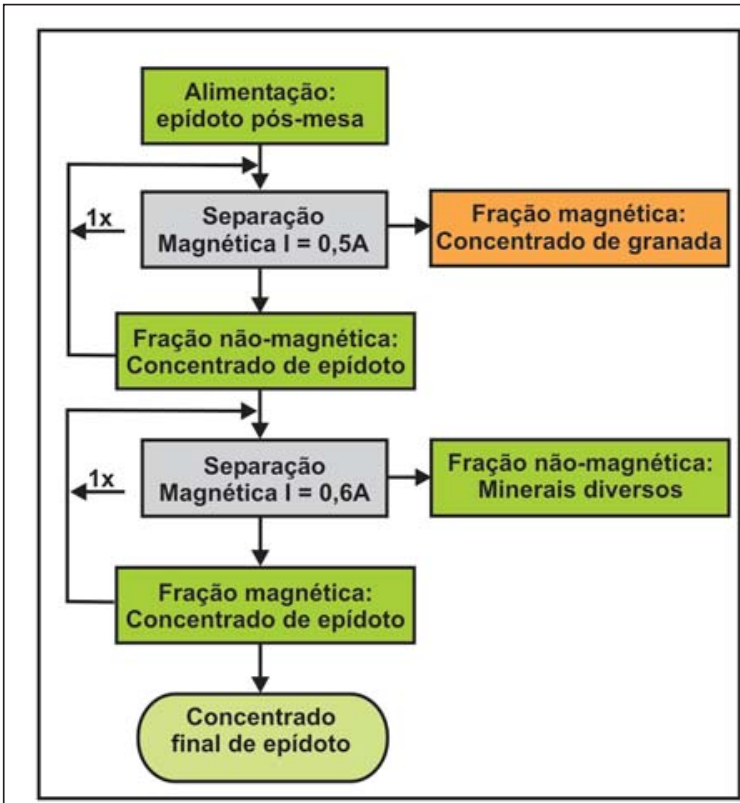

(a)

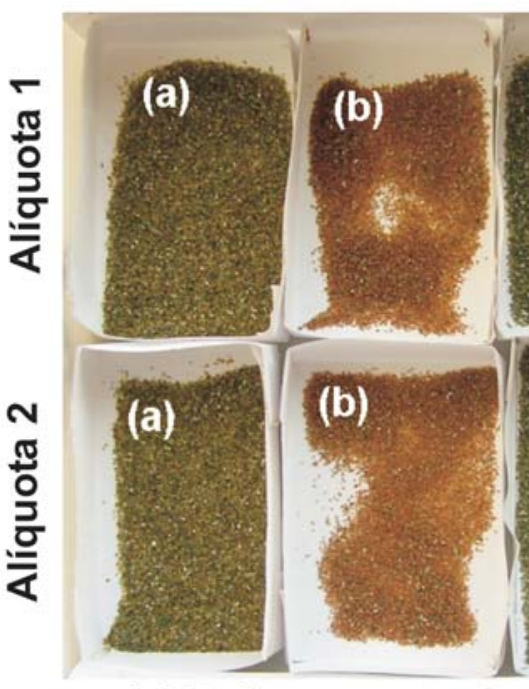

(a) Pré-concentrado

(c) $\mathrm{fNM} ; \mathrm{I}=0,6 \mathrm{~A}$

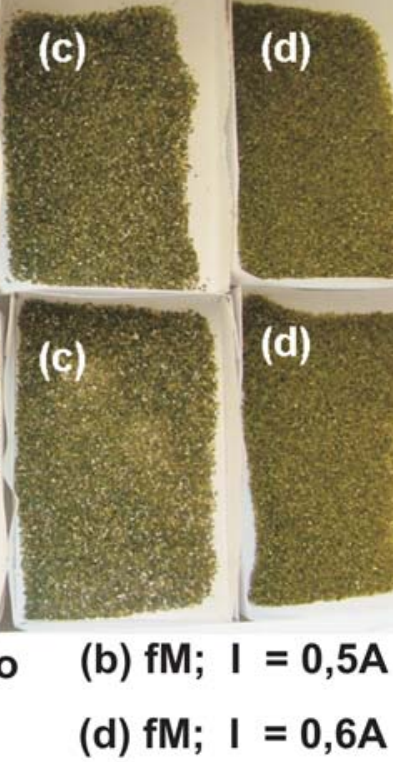

(b)

Figura 2 - (a) Fluxograma do procedimento proposto para a concentração de epídoto e (b) frações obtidas para duas alíquotas.

com o difratograma da amostra monocristalina (e-m) e ambos com o padrão de epídoto. Já na fração magnética relacionada à passagem com I = 0,5 A (e-r), ocorrem andradita $\left(\mathrm{Ca}_{3} \mathrm{Fe}_{2}\left(\mathrm{SiO}_{4}\right)_{3}\right)$, epídoto e calcita.

A Tabela 3 apresenta os resultados dos refinamentos dos difratogramas da Figura 3. Observa-se que o epídoto corresponde à fase mineral predominante $(74,9 \%)$ na amostra tida como o concentrado de epídoto (e-c). Observa-se também a significativa concentração de andradita na amostra e-r, tida como "rejeito" da separação magnética. Duas outras fases não identificadas originalmente nos difratogramas foram notadas após o refinamento: a tremolita $\left(\mathrm{Ca}_{2} \mathrm{Mg}_{5}\left(\mathrm{Si}_{8} \mathrm{O}_{22}\right)(\mathrm{OH})\right)$, que ocorre na amostra e-pm, e o piropo $\left(\mathrm{Mg}_{3} \mathrm{Al}_{2}\left(\mathrm{SiO}_{4}\right)_{3}\right)$, que ocorre na amostra e-r. Comparando os teores de epídoto das amostras e-pm e e-c, nota-se que houve um aumento de quase $20 \%$.

A Tabela 4 apresenta os resultados da análise dos elementos maiores por fluorescência de raios $X$. Observa-se que todas as amostras possuem os óxidos presentes no epídoto: $\mathrm{Al}_{2} \mathrm{O}_{3}, \mathrm{Fe}_{2} \mathrm{O}_{3}, \mathrm{SiO}_{2}$ e CaO. Esses óxidos também compõem
Tabela 2 - Frações obtidas a partir do procedimento para concentração do epídoto na faixa de 150 a $300 \mu \mathrm{m}$.

\begin{tabular}{c|c|c|c|c|c}
\hline \multirow{2}{*}{ Etapa } & \multirow{2}{*}{ I (A) } & \multicolumn{2}{|c|}{ Alíquota 1 (2,52 g) } & \multicolumn{2}{c}{ Alíquota 2 (2,54 g) } \\
\cline { 3 - 6 } & & $\mathbf{f M ~ ( g )}$ & fNM (g) & $\mathbf{f M ~ ( g )}$ & fNM (g) \\
\hline 1 & 0,50 & 0,40 & 2,06 & 0,40 & 2,11 \\
\hline 2 & 0,50 & 0,02 & 2,00 & 0,01 & 2,10 \\
\hline 3 & 0,60 & 1,13 & 0,87 & 1,13 & 0,95 \\
\hline 4 & 0,60 & 1,06 & 0,05 & 1,08 & 0,03 \\
\hline
\end{tabular}

fM: fração magnética. fNM: fração não magnética.

Tabela 3 - Quantificação (\%) das fases minerais resultantes do refinamento dos difratogramas de raios $\mathrm{X}$.

\begin{tabular}{c|c|c|c|c}
\hline & e-pm & e-r & e-c & e-m \\
\hline Andradita & 15,2 & 78,5 & 6,1 & - \\
\hline Calcita & 9,7 & - & 12,9 & - \\
\hline Epídoto & 55,2 & 12,3 & 74,9 & 100 \\
\hline Piropo & - & 3,8 & - & - \\
\hline Quartzo & 12,3 & 5,4 & 4,7 & - \\
\hline Tremolita & 7,5 & - & 1,4 & - \\
\hline
\end{tabular}

- Não detectado. 
pelo menos uma das outras fases minerais detectadas por difratometria de raios X, impedindo qualquer comparação isolada. Porém pode-se constatar que os teores dos óxidos $\mathrm{CaO}$ e $\mathrm{Fe}_{2} \mathrm{O}_{3}$ são próximos para as amostras e-m e e-c, enquanto que o teor de $\mathrm{Fe}_{2} \mathrm{O}_{3}$ é relativamente maior para e-r.

Os teores dos óxidos constituintes apresentados na Tabela 4 confirmam a presença das fases quantificadas pelo refinamento dos difratogramas de raios $\mathrm{X}$. O maior teor de $\mathrm{Fe}_{2} \mathrm{O}_{3}$, na amostra e-r, é um reflexo da predominância da andradita nessa fase. Os maiores teores de $\mathrm{SiO}_{2}$ e $\mathrm{MgO}$, na amostra e-pm, estão relacionados à maior presença do quartzo e da tremolita. Comparando-se os teores de $\mathrm{MgO}$ das quatro amostras, fica confirmado que a tremolita ainda está presente no concentrado de epídoto. As fases constituintes da amostra e-pm são aquelas que mais se aproximam da amostracabeça. Segundo Carvalho et al. (2002), as pilhas de rejeito da usina de beneficiamento da scheelita são constituídas predominantemente por calcita (40\%), quartzo (23\%), grossulária (15\%), vesuvianita (3\%), tremolita (2\%), diopsídio (2\%) e epídoto (1\%). A principal discrepância em relação à nossa amostra deve-se à presença da grossulária $\left(\mathrm{Ca}_{3} \mathrm{Al}_{2}\left(\mathrm{SiO}_{4}\right)_{3}\right)$ e não da andradita.

\section{Conclusão}

A partir de um fragmento de rocha de tactito, constituído por epídoto, calcita, andradita, quartzo e tremolita, obtiveram-se um concentrado de epídoto com teor de $75 \%$ para a faixa entre 150 a $300 \mu \mathrm{m}$, associando-se concentração em mesa vibratória, e quatro etapas de separação magnética com correntes de 0,5 e 0,6 A (0,5 e 0,6 T). A caracterização mineralógica mostrou que a principal contaminação do concentrado de epídoto provém da calcita. Considerando a diferença de densidade entre o epídoto e a calcita, acredita-se que o fracionamento em meio denso poderá elevar o teor do concentrado de epídoto para cerca de 90 $\%$. Pela semelhança notada entre as mineralogias, o procedimento proposto

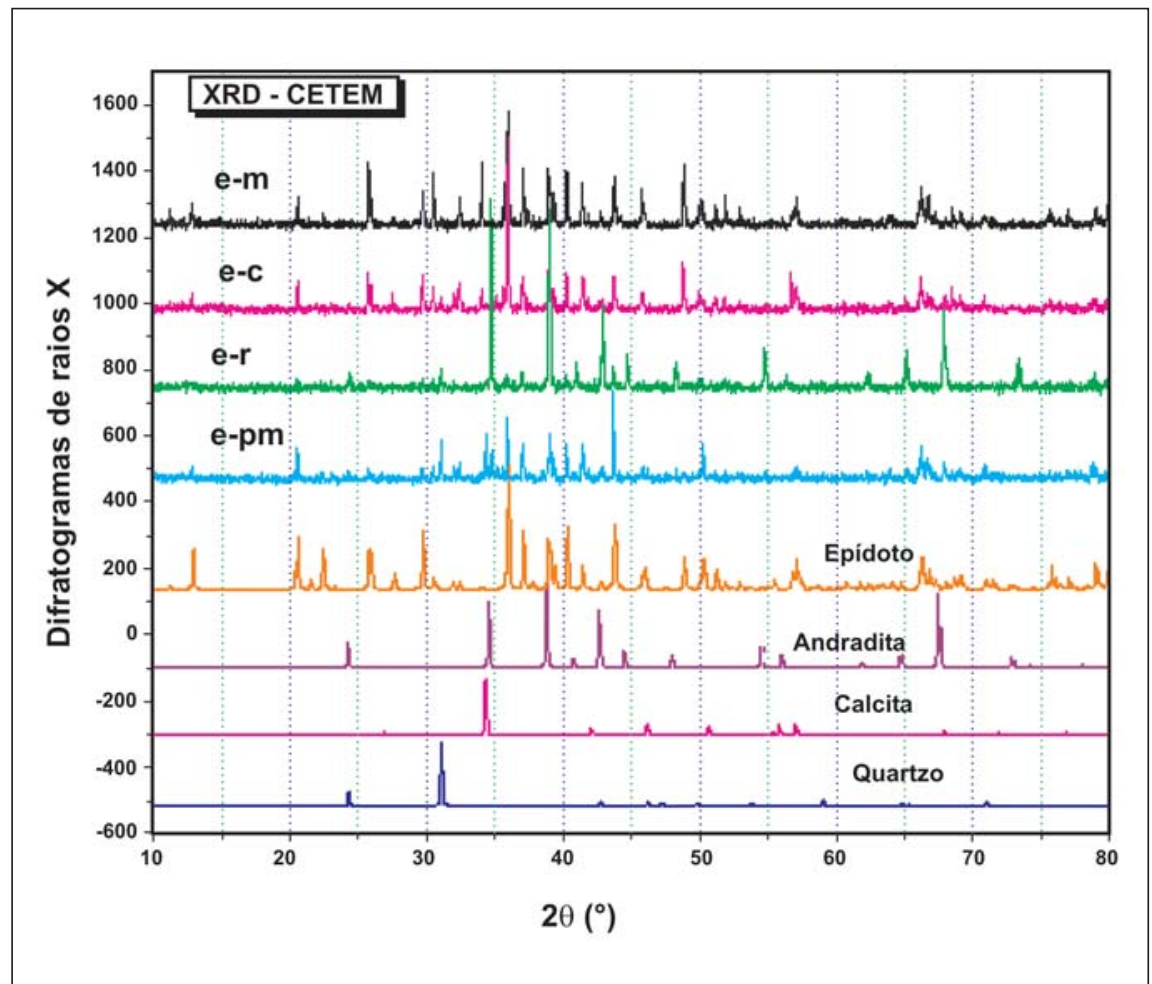

Figura 3 - Difratograma de raios $X$ das frações de pré-concentrado (e-pm), magnética para I = 0,5 A (e-r), magnética para I = 0,6 A (e-c) e monocristal de epídoto $(e-m)$.

Tabela 4 - Principais óxidos detectados na análise semiquantitativa por fluorescência de raios $X$

\begin{tabular}{c|c|c|c|c}
\hline \multirow{2}{*}{ Óxido } & \multicolumn{4}{|c}{ Concentração (\%) } \\
\cline { 2 - 5 } & e-pm & e-r & e-c & e-m \\
\hline $\mathrm{Al}_{2} \mathrm{O}_{3}$ & 10,0 & 6,1 & 8,7 & 10,2 \\
\hline $\mathrm{Fe}_{2} \mathrm{O}_{3}$ & 13,7 & 22,8 & 16,7 & 16,3 \\
\hline $\mathrm{SiO}_{2}$ & 33,6 & 27,3 & 27,1 & 25,6 \\
\hline $\mathrm{CaO}$ & 22,6 & 27,0 & 22,0 & 21,6 \\
\hline $\mathrm{MgO}$ & 3,1 & 1,0 & 1,8 & 0,6 \\
\hline $\mathrm{MnO}^{2}$ & 0,7 & 1,7 & 0,5 & 0,3 \\
\hline $\mathrm{Na}_{\mathbf{2}} \mathrm{O}$ & 0,1 & - & - & - \\
\hline $\mathbf{P}_{\mathbf{2}} \mathrm{O}_{5}$ & 0,1 & 0,3 & 0,3 & 0,2 \\
\hline $\mathrm{SrO}$ & 0,1 & $\mathrm{nd}$ & 0,1 & 0,1 \\
\hline $\mathrm{TiO}_{2}$ & 0,4 & 0,5 & 0,1 & 0,1 \\
\hline
\end{tabular}

- Não detectado. 
poderá ser aplicado às pilhas de rejeito da usina de beneficiamento da scheelita.

\section{Agradecimentos}

Os autores (EFSJr) agradecem ao Programa PIBIC/CETEM/CNPqpela bolsa de iniciação científica.

\section{Referências} bibliográficas CARVALHO, E.B., LIMA,R.F.S., PETTA, R.A., PAULO, J.B.A., SOUZA, L.C.
Caracterização de rejeitos provenientes da usina de beneficiamento do minério da Mina Brejuí/RN. In: XIX ENTMME, 2002, Recife, Anais...v. 1, p.75-81.

CURVO, E.A.C., HADLER NETO, J.C., IUNES, P.J., GUEDES, S., TELLO, C.A., PAULO, S.R., HACKSPACHER, P.C., PALISSARI, R., MOREIRA, P.A.F.P. On epidote fission track dating. Rad. Measurements, v. 39, p.641-645, 2005.

CURVO, E.A.C. Estudo da datação por traços de fissão em epídoto. Campinas: IFGW/ UNICAMP, 2002. 50p. (Dissertação de Mestrado).

DANA-HURLBUT. Manual de mineralogia. São Paulo: L.T.C. v.2, 457p. 1959.

FREI, D., LIEBSCHER, A., WITTENBERG, A., CLIFF, S. SHAW, J. Crystal chemical controls on rare earth element partioning between epidote-group minerals and melts: an experimental and theoretical study. Contr. Mineral. Petrol., v. 146, p.192-204, 2003.

RALPH, J., RALPH, I. www.mindat.org/min-1389.html (acessado em 29/11/2007).

SULLASI, H.L., SILVA JR, E.F., KHOURY, H.J., WATANABE, S., GUZZO, P.L., THOMAS FILHO, L., BARRETO, S.B. Thermoluminescence properties of epidote from Borborema Province under $\gamma$-irradiation. In: INTERNATIONAL NUCLEAR ATLANTIC CONFERENCE. Anais... Santos, ABEN, cd-room, p. 1-6. 2007.

Artigo recebido em 24/01/2008 e aprovado em 31/05/2008.

\section{A REM tem novo endereço:}

\section{Rua Carlos Walter Marinho Campos, 57 Bairro: Vila Itacolomy 35400-000 - Ouro Preto - MG}

$\star * * * * * * * * * * * * * *$

www.rem.com.br 